\title{
Linear and Nonlinear Computations of the 1992 Nicaragua Earthquake Tsunami
}

\author{
KenJi Satake ${ }^{1}$
}

\begin{abstract}
Numerical computations of tsunamis are made for the 1992 Nicaragua earthquake using different governing equations, bottom frictional values and bathymetry data. The results are compared with each other as well as with the observations, both tide gauge records and runup heights. Comparison of the observed and computed tsunami waveforms indicates that the use of detailed bathymetry data with a small grid size is more effective than to include nonlinear terms in tsunami computation. Linear computation overestimates the amplitude for the later phase than the first arrival, particularly when the amplitude becomes large. The computed amplitudes along the coast from nonlinear computation are much smaller than the observed tsunami runup heights; the average ratio, or the amplification factor, is estimated to be 3 in the present case when the grid size of 1 minute is used. The factor however may depend on the grid size for the computation.
\end{abstract}

Key words: Tsunami, numerical computation, finite-difference method, Nicaragua earthquake.

\section{Introduction}

Numerical computation has become a powerful and popular tool to study tsunamis. In this topical issue, a number of papers are found on modeling recent tsunamis for various purposes such as to reproduce the observed tsunamis, to estimate unobserved offshore tsunami heights or the effects on coastal structures, or to study earthquake source processes. SHUTO (1991), in a review of tsunami numerical computations, mentioned that numerical computations can predict runup heights with errors smaller than $15 \%$. Tsunami runup heights of the recent tsunamis such as the 1992 Nicaragua tsunami, however, seem to be much larger than those predicted using numerical computations from seismological fault models.

In this paper, I describe a numerical computation method of tsunamis with the 1992 Nicaragua earthquake tsunami as an example. I discuss various factors that affect the computations: the governing equations, linear and nonlinear shallow water equations; bottom frictional values; bathymetric data and the grid size. The

\footnotetext{
'Department of Geological Sciences, University of Michigan, Ann Arbor, MI 48109-1063, U.S.A.
} 
computations are compared with the observed data, both tide gauge records and runup heights.

\section{The 1992 Nicaragua Earthquake and Tsunamis}

\subsection{Seismolgical Analyses}

The 1992 Nicaragua earthquake occurred at 00 h $15 \mathrm{~m} 57.5 \mathrm{~s}$ on September 2 (GMT). The seismic waves from the Nicaragua earthquake were recorded on global digital seismic networks and the data were available through computer network in almost real time. The aftershock epicenters located by the National Earthquake Information Service, USGS, were also available by computer network. Seismological analyses of these data (IDE et al., 1993; KANAMORI and KIKUCHI, 1993; SATAKe et al., 1993; Velasco et al., 1994; KIKUCHI and KANAMORI, 1995) showed that the focal mechanism exhibits a thrust-type fault, with a plane dipping shallowly toward the northeast and the strike parallel to the Middle America trench. This is consistent with a subduction of the Cocos plate beneath the Caribbean plate. The seismic moment $M_{0}$ estimated from long-period seismic waves ranges $3-4 \times 10^{20} \mathrm{Nm}\left(M_{W}=7.6-7.7\right)$. The duration of the rupture process is about $100 \mathrm{~s}$, unusually long for its size. Aftershocks occurred in an area about $200 \mathrm{~km}$ along the strike and $100 \mathrm{~km}$ downdip of the trench (Figure 1).

\subsection{Observed Tsunami Data}

The tsunami runup heights along the Nicaraguan coast were measured by field surveys soon after the earthquake and are reported elsewhere (ABE et al., 1993; BAPTISTA et al., 1993). The maximum runup height was $9.9 \mathrm{~m}$ above mean sea level (MSL), but the runup heights are mostly between 3 and $8 \mathrm{~m}$ along the Nicaraguan coast. The tsunamis were also recorded on tide gauges at Corinto and Puerto Sandino as shown in Figure 2. The Corinto tide gauge record shows an impulsive tsunami with its maximum at $61 \mathrm{~min}$ after the earthquake origin time. There is a small fall (about $10 \mathrm{~cm}$ ) of sea level before the first rise. The trough-to-peak amplitude is $49 \mathrm{~cm}$. The Puerto Sandino record also shows a sea-level fall of about $10 \mathrm{~cm}$, followed by a very abrupt sea level rise which made the gauge go off-scale at $65 \mathrm{~min}$ after the origin time. The trough-to-peak amplitude is at least $117 \mathrm{~cm}$. TADEPALLI and SYNOLAKIS (1994) called such a waveform, a small trough followed by a larger peak, a leading depression $N$ wave.

\subsection{Fault Models}

The fault parameters of this earthquake have been estimated from seismological analysis (IDE et al., 1993) and from tsunami modeling (IMAMURA et al., 1993; 


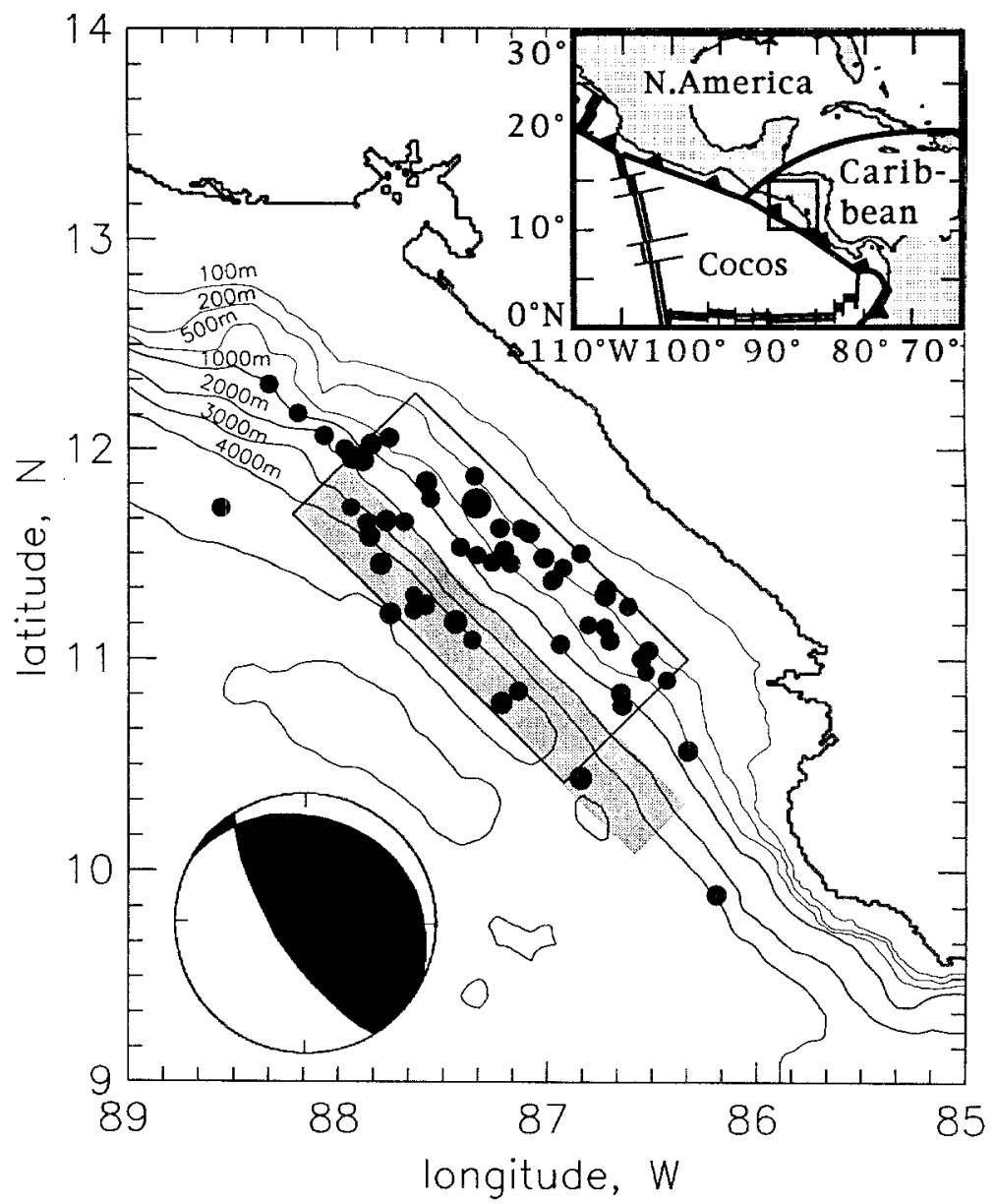

Figure 1

The source region of the 1992 Nicaragua earthquake. Solid circles shows the aftershocks within 1 day of the main shock (from Preliminary Determination of Epicenters). Open frame shows the horizontal projection of the seismological fault model, whereas the shaded frame is for the tsunami fault model. The focal mechanism of the main shock (SATAKE et al., 1993) is also shown. The inset shows the tectonic framework of central America.

Titov and SyNOLAKIS, 1993). IDE et al. (1993) estimated that the fault size is $200 \mathrm{~km} \times 100 \mathrm{~km}$ and the average slip is $0.5 \mathrm{~m}$. Imamura et al. (1993) made linear tsunami computations from a similar model and showed that the computed tsunamis are too small, a factor of 5.6 to 10, compared to the observed runup heights. They then suggested that the fault slip is larger by the factor than the seismological model; their seismic moment is $3 \times 10^{21} \mathrm{Nm}$, an order of magnitude larger than the seismological results. TITov and SyNOLAKIS (1993) roughly reproduced the 

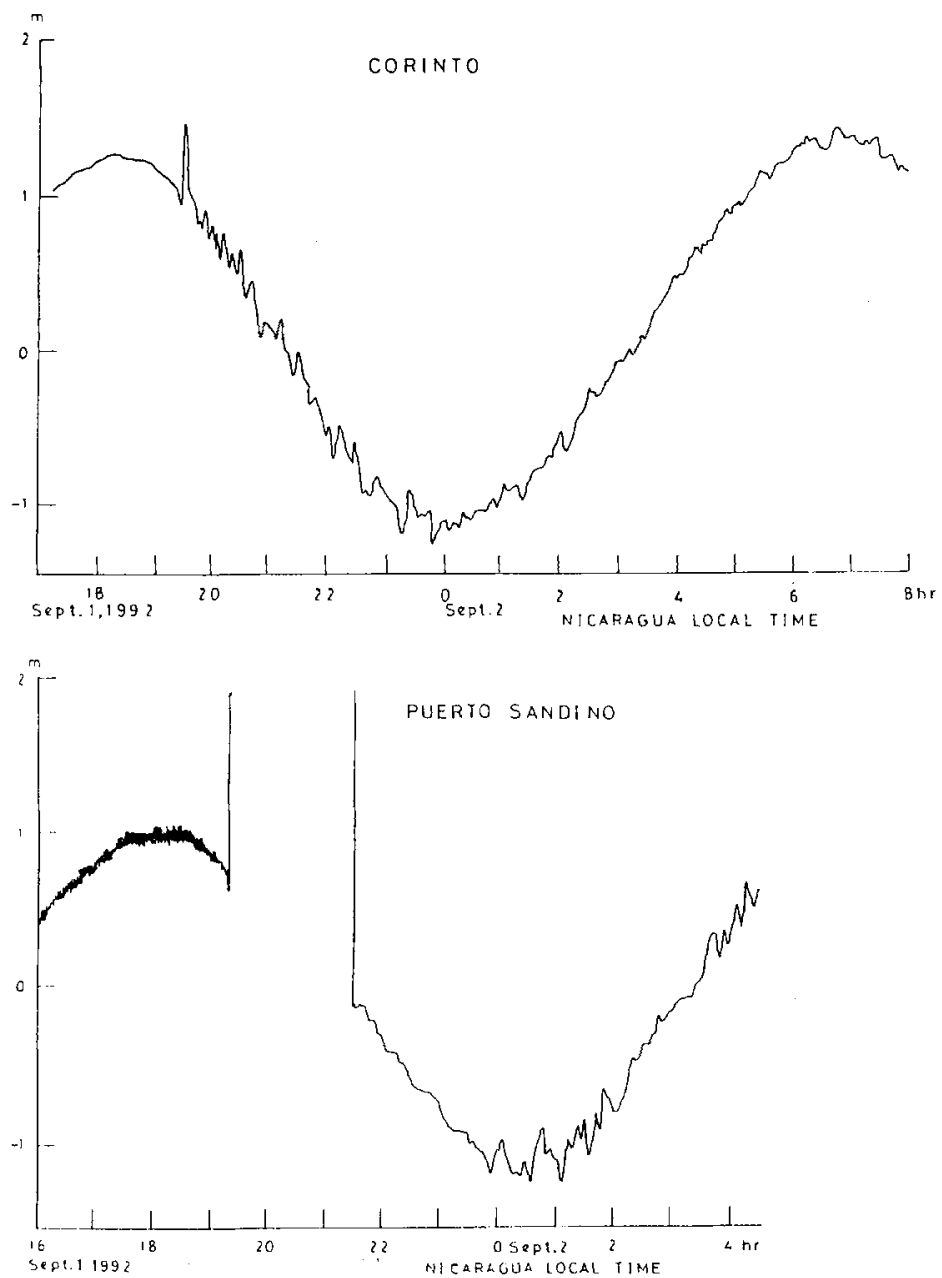

Figure 2

Tide gauge records at Corinto and Puerto Sandino showing the tsunamis (ABE et al., 1993). The Puerto Sandino record went off-scale soon after the first tsunami arrival. Time scale is in the Nicaragua local time in which the earthquake origin time was $18: 16$.

observed runup heights from this seismic moment, using a combination of a twodimensional nonlinear equation with a one-dimensional runup equation.

Recently, SATAKE (1994) estimated the fault parameters that are consistent with both seismological and tsunami data. Tsunami waveforms recorded on tide gauges required the fault width to be $40 \mathrm{~km}$, much narrower than the aftershock area, and it extends only into the upper $10 \mathrm{~km}$ of the ocean bottom. Slip amount on the fault is estimated to be $3 \mathrm{~m}$ from the comparison of tsunami amplitudes on tide gauges. The fault length is estimated to be $250 \mathrm{~km}$, slightly longer than the aftershock area, 


\section{Seismic Model}

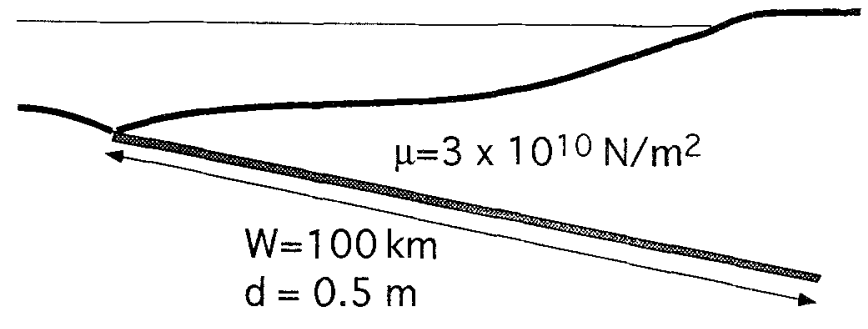

\section{Tsunami Model}

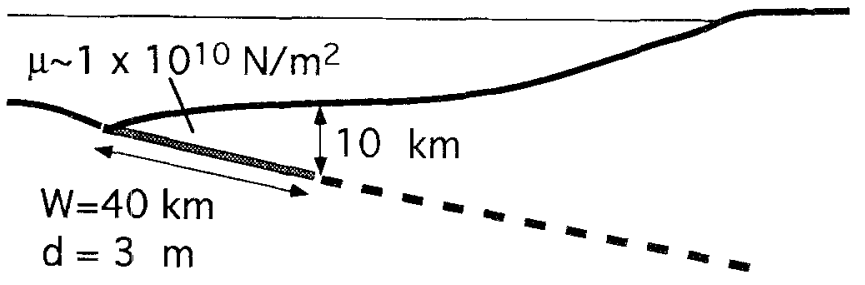

Figure 3

Schematic cross-sectional view of the seismic fault model (top: IDE et al., 1993) and tsunami fault model (bottom: SATAKE, 1994). Both give the same seismic moment, but very different tsunamis.

from comparison of the tsunami height distribution. If the faulting occurred at such a shallow depth, the rigidity around the fault may be small. If we use $1 \times 10^{10} \mathrm{~N} / \mathrm{m}^{2}$ as the average rigidity for the top $10 \mathrm{~km}$ of crust, compared to a standard value of $3-4 \times 10^{10} \mathrm{~N} / \mathrm{m}^{2}$ for subduction-zone earthquakes, then the seismic moment becomes $3 \times 10^{20} \mathrm{Nm}$. This value is consistent with the seismic observations, 3$4 \times 10^{20} \mathrm{Nm}$. In the following, I use this fault model as the tsunami source model (Figure 3). SATAKe (1994) showed that the seismic and tsunami models produce very different tsunamis, while they are indistinguishable from seismic observations.

\section{Shallow Water Theory}

\subsection{Linear and Nonlinear Equations}

Tsunamis are usually treated as shallow water waves, which is also referred to as long waves. Shallow water theory is valid when the wavelength is much larger 
than the water depth, which applies to the source region of most earthquake tsunamis. The vertical acceleration is ignored and the horizontal velocity is assumed to be uniform. In other words, water from bottom to surface moves uniformly. The equation of motion, or conservation of momentum, can be written as (e.g., MADER, 1988; KowaliK and MurTy, 1993)

$$
\frac{\partial V}{\partial t}+(V \cdot \nabla) V=-g \nabla h-C_{f} \frac{V|V|}{d+h}
$$

where $V$ is the depth-averaged horizontal velocity vector, $h$ is the water elevation or tsunami amplitude, $d$ is the water depth and $g$ is the gravitational acceleration. The first term on the left-hand side represents local acceleration, the second term is nonlinear advection term. The first term on the right-hand side represents pressure gradient, or restoring force due to gravity, and the second term is bottom friction where $C_{f}$ is the nondimensional friction coefficient.

When the tsunami amplitude $h$ is very small compared to water depth $d$, we can use "small amplitude" approximation, $h \ll d$. Further, if we can ignore the bottom friction, then the above equation can be linearized. The linear long wave equation is

$$
\frac{\partial V}{\partial t}=-g \nabla h
$$

Linear theory is valid in deep ocean or small amplitude tsunamis. The advantage of linear theory is its "linearity." Since the slip amount on the fault and the crustal deformation are linearly related, the tsunami amplitude is also linearly related to the slip amount. Therefore, once we compute tsunamis for a certain amount of slip on the fault, tsunami amplitude for different slip amount can be easily estimated by multiplication of the appropriate factor. This principle has been used for inversion of tsunami waveforms to estimate the slip distribution on an earthquake fault (e.g., SATAKE, 1989).

The equation of continuity, or conservation of mass, is written as

$$
\frac{\partial(d+h)}{\partial t}=-\nabla \cdot\{(d+h) V\}
$$

Note that water depth, $d$, may be a function of time because of the coseismic bottom movement.

\subsection{Bottom Friction}

The bottom friction of tsunamis has not been well-known and various forms and values adopted in other areas have been used. In engineering hydraulics, two frictional coefficients are often used: the De Chézy coefficient $C$ and the Manning's roughness coefficient $n$. These have different dimensions. The nondimensional 
frictional coefficient $C_{f}$ in equation (1) is related to these as

$$
C_{f}^{2}=\frac{g}{C^{2}}
$$

and

$$
C_{f}=\frac{g n^{2}}{(d+h)^{1 / 3}} .
$$

The Manning's roughness coefficient $n$ is used for a uniform turbulent flow on a rough surface. It indicates that the bottom friction varies with water depth.

A typical value of $C_{f}$ for tidal flow is $2-5 \times 10^{-3}$ in rivers and $2.4-2.8 \times 10^{-3}$ in shallow sea (e.g., Dronkers, 1964). For runup of solitary waves, KajIURA (1984) estimated that $C_{f} \sim 1 \times 10^{-2}$ from comparisons of theory and experiments. SYNOLAKIS and SKJELBREIA (1993) compiled post-breaking solitary wave data that range $C_{f}=4$ to $9 \times 10^{-2}$ for beach slopes of $1: 166$ to $1: 50$. They commented that the value for nonbreaking waves or waves before breaking would be smaller. KowALIK and WHITMORE (1991) used the value of $C_{f}=3.3 \times 10^{-3}$ for tsunamis. AIDA et al. (1988) used different values for their numerical computation of tsunami runup; $C_{f}=5 \times 10^{-3}$ for coastal water and $1 \times 10^{-2}$ on land without obstacles.

A typical value of $n$ for coastal water is $0.03 \mathrm{~m}^{-1 / 3} \mathrm{~s}$ (e.g., BAPTISTA et al., 1989). If we use this value, the frictional coefficient $C_{f}$ becomes $2.3 \times 10^{-3}$ and $1 \times 10^{-2}$ for a total depth $(d+h)$ of $50 \mathrm{~m}$ and $0.6 \mathrm{~m}$, respectively, and they agree well with the above observational values of tidal flow and runup of solitary waves.

In this paper, I use the formulation (4) with $n=0.03 \mathrm{~m}^{-1 / 3} \mathrm{~s}$. For comparison, I also calculate for two depth-independent frictional values, $C_{f}=3 \times 10^{-3}$ and $1 \times 10^{-2}$, that may correspond to tidal flow and tsunami runups.

\section{Numerical Computations of Tsunamis}

\subsection{Finite-difference Method}

We take the spherical coordinate system $(r, \theta, \phi)$ with the origin at the earth's center, but $r$ is constant and equal to the earth's radius $R$. Note that $\theta$ is colatitude and measured southward from the North Pole and $\phi$ corresponds to longitude measured eastward from the Greenwich meridian. If we write the east and south components of the depth-averaged horizontal velocity $V$ as $u$ and $v$, respectively, then the equation of motion (1) can be written in each component as

$$
\begin{aligned}
& \frac{\partial u}{\partial t}+\frac{u}{R \sin \theta} \frac{\partial u}{\partial \phi}+\frac{v}{R} \frac{\partial u}{\partial \theta}=-\frac{g}{R \sin \theta} \frac{\partial h}{\partial \phi}-C_{f} \frac{u \sqrt{u^{2}+v^{2}}}{d+h} \\
& \frac{\partial v}{\partial t}+\frac{u}{R \sin \theta} \frac{\partial v}{\partial \phi}+\frac{v}{R} \frac{\partial v}{\partial \theta}=-\frac{g}{R} \frac{\partial h}{\partial \theta}-C_{f} \frac{v \sqrt{u^{2}+v^{2}}}{d+h}
\end{aligned}
$$


and the equation of continuity (3) becomes

$$
\frac{\partial(d+h)}{\partial t}=-\frac{1}{R \sin \theta}\left[\frac{\partial\{u(d+h)\}}{\partial \phi}+\frac{\partial\{v \sin \theta(d+h)\}}{\partial \theta}\right]
$$

The equations (5) and (6) are solved by finite-difference method. In this paper, the staggered leap-frog method is used. For the advection term, upwind difference scheme is used (e.g., PRESs et al., 1992). On the ocean boundary, radiation condition, in which the tsunami wave is assumed to go out without changing its shape, is assumed. On land boundary (coast), total reflection is assumed. The coastal boundary is fixed; i.e., no runup on land is considered.

The time step of computation is determined to satisfy the stability condition (Courant condition) of the finite-difference computation. It is set to $5 \mathrm{~s}$ in the present case. Numerical computations of tsunamis are made for three hours of tsunami propagation. The tsunami waveforms are output on coastal points including the two tide gauge locations. The computations were made using both linear and nonlinear shallow water equations.

\subsection{Bathymetry Data}

The tsunami computational area extends from $9^{\circ} \mathrm{N}$ to $14^{\circ} \mathrm{N}$ and $89^{\circ} \mathrm{W}$ to $85^{\circ} \mathrm{W}$. The ETOPO5 data, now on the Global Relief CD-ROM and available from the National Geophysical Data Center, NOAA, for the corresponding region is shown in Figure 4 (left). The ETOPO5 bathymetry data are reasonably accurate in the deep $(>1000 \mathrm{~m})$ ocean, but known to be inaccurate in shallow water. As can be seen in the figure, the ETOPO5 data shows very shallow (about $10 \mathrm{~m}$ depth) elongated bank running parallel to the coast between $11^{\circ}$ and $12^{\circ} \mathrm{N}$, but such a bank does not exist in any nautical charts. In addition, the coastal shape cannot be accurately represented by 5 minute grids.

I compiled the bathymetry data with a grid size of 1 minute (about $1.6 \mathrm{~km}$ ) as shown in Figure 4 (right). The number of grid points is $72,000(240 \times 300)$. I used nautical charts (Defense Map Agency Nos. 21520, 21540 and 21550) and manually updated the bathymetry data for the coastal region (depth $<1000 \mathrm{~m}$ ). The depths for deeper grids are interpolated from the ETOPO5 data. The shallowest depth along the coast is about $10 \mathrm{~m}$.

Around the two tide gauge stations (Corinto and Puerto Sandino), I also prepared bathymetry data with finer (12 seconds) grid size. They are shown in Figure 5. The higher resolution (up to 1:12,500) nautical charts (DMA 21524 and 21542) are used to make the gridded data. The shallowest depth is as small as $1 \mathrm{~m}$, although the depth at the Corinto tide gauge station is $10 \mathrm{~m}$ and Puerto Sandino is $4 \mathrm{~m}$. 

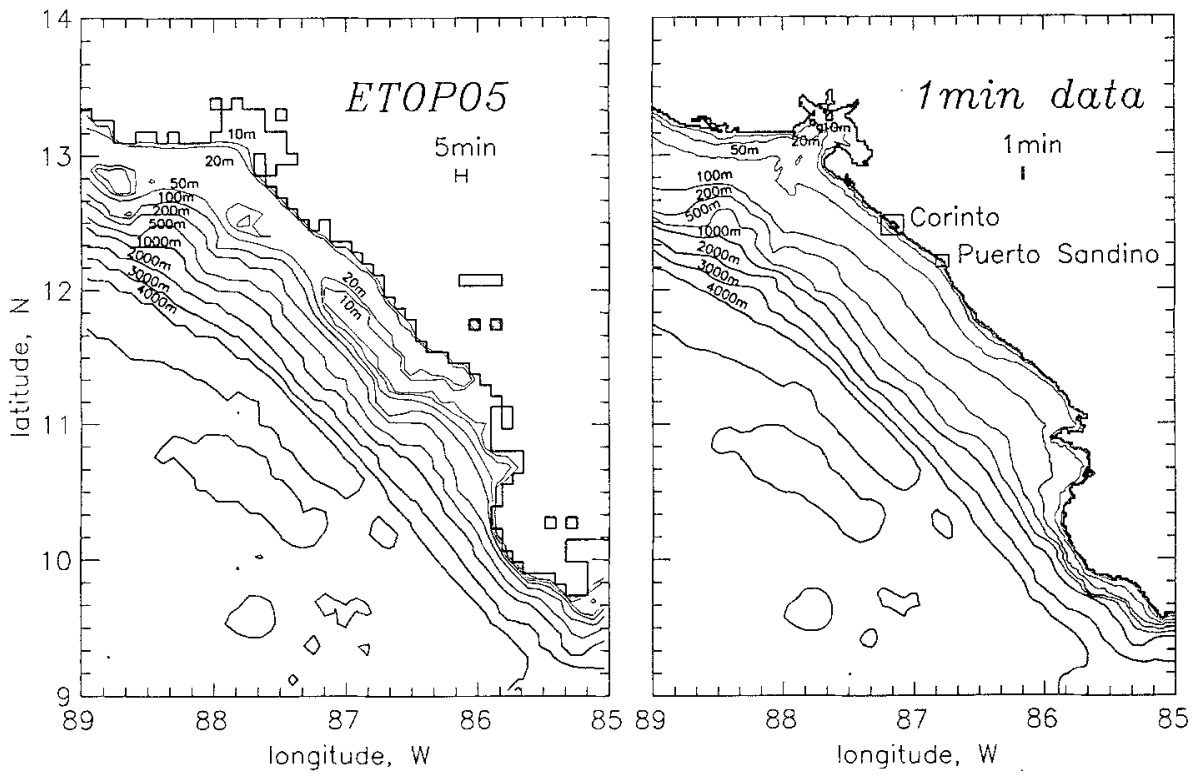

Figure 4

Comparison of the ETOPO5 data (left) and the 1 minute gridded data used in this study (right). Around the Corinto and Puerto Sandino tide gauge stations (shown by squares), more detailed bathymetry data (see Figure 5) are used.

\subsection{Initial Condition}

The initial bottom displacement is computed from the fault parameters estimated by SATAKE (1994). They are: the fault length $250 \mathrm{~km}$, the fault width $40 \mathrm{~km}$, the fault extends from ocean bottom to $10 \mathrm{~km}$ depth with a dip angle of $15^{\circ}$. The
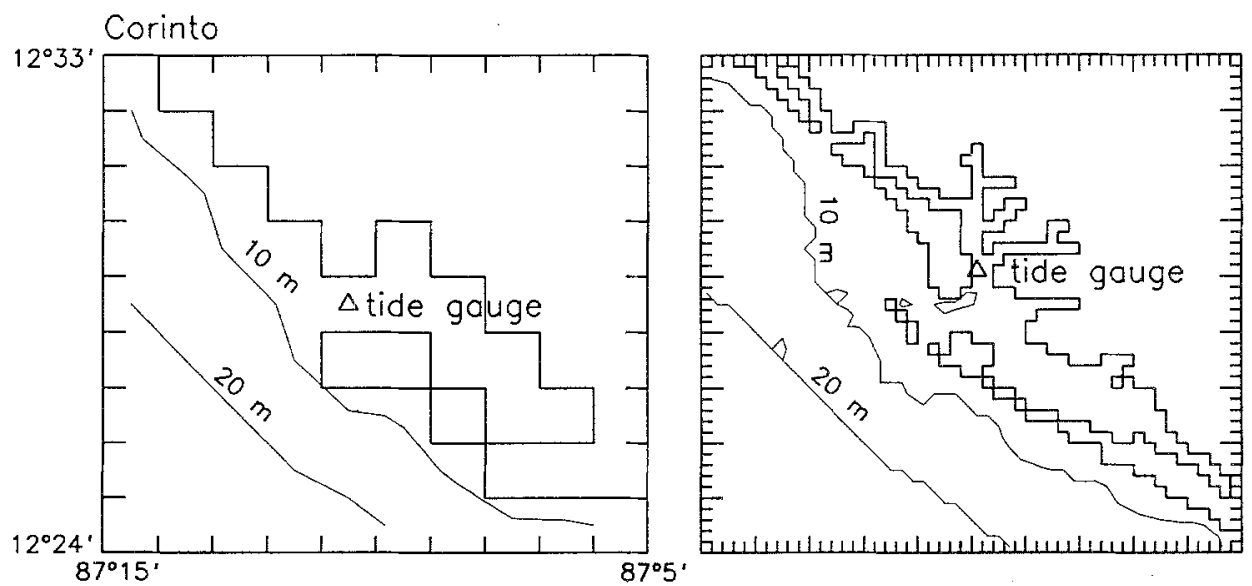

Figure 5(a) 


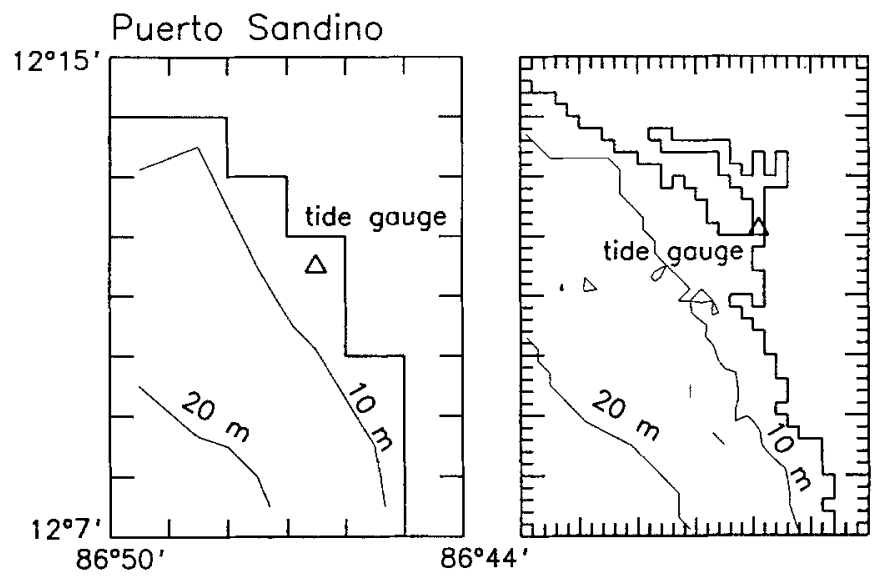

Figure 5(b)

Figure 5

Gridded bathymetry around Corinto (a) and Puerto Sandino (b) tide gauge stations. At each station, the left panel shows 1 minute grid and the right is $1 / 5$ minute (12 seconds) grid.

slip on the fault is a pure dip slip (slip angle $90^{\circ}$ ) and the amount is $3 \mathrm{~m}$. The fault strike is $315^{\circ}$ and the location is shown in Figure 6 . The vertical crustal deformation is calculated from these parameters (e.g., OKADA, 1985) and also shown in Figure 6. The maximum uplift is about $133 \mathrm{~cm}$ and occurs at the top edge of the fault, which is located at the trench axis. The maximum subsidence of $56 \mathrm{~cm}$ occurs above the deeper end of the fault, which is closer to the coast. The tsunami waveforms on the Nicaraguan coast are therefore expected be leading depression $N$ waves, as actually observed. TADEPALLI and SYNOLAKIS (1994) showed that the runup heights from such a wave are larger than solitary waves or leading elevation $N$ waves.

\section{Computation of Tide Gauge Records}

\subsection{Effect of Grid Size}

The tsunami waveforms are first computed at the two tide gauge locations, Corinto and Puerto Sandino, both on 1 minute and 12-second grid systems, and they are compared with the observation (Figure 7). As can be seen in Figure 7, the computed waveforms are different on the 1 minute and 12-second grid systems. The latter is closer to the observed waveforms. In particular, the sharp rise of water at Puerto Sandino could be reproduced only by using the 12-second grids. The 


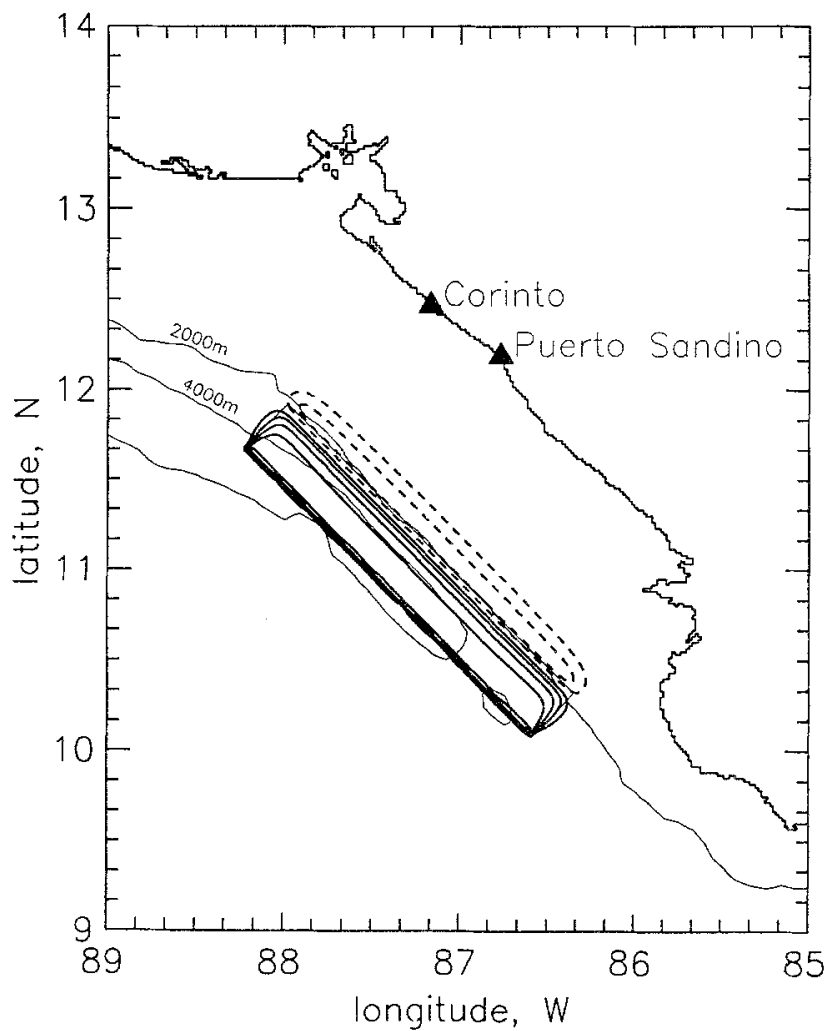

Figure 6

The initial bottom deformation overlaid on bathymetry. The solid lines are for uplift and the dashed lines are for subsidence. The contour interval is $20 \mathrm{~cm}$. The location of two tide gauge stations are also shown.

computation on the 1-minute grid system predicted earlier arrival of tsunami than both that on the 12-second grids and the observed. This is not surprising if we look at Figures 5 . The 1 minute grid system cannot represent the coastal topography around the stations very well.

As far as the same bathymetric data are used, the computed waveforms are similar for the linear and nonlinear equations. The amplitude at Puerto Sandino on 12-second grids are different, but the waveforms are still similar. On 1-minute grid system, both amplitude and waveforms are very similar, because of the much smaller amplitude than the water depth. In other words, the tsunamis can be well approximated as linear shallow water waves.

The above comparison shows that it is more important to use detailed and accurate bathymetry data than to include nonlinear terms for accurate tsunami computation, as far as the tide gauge records are concerned. 

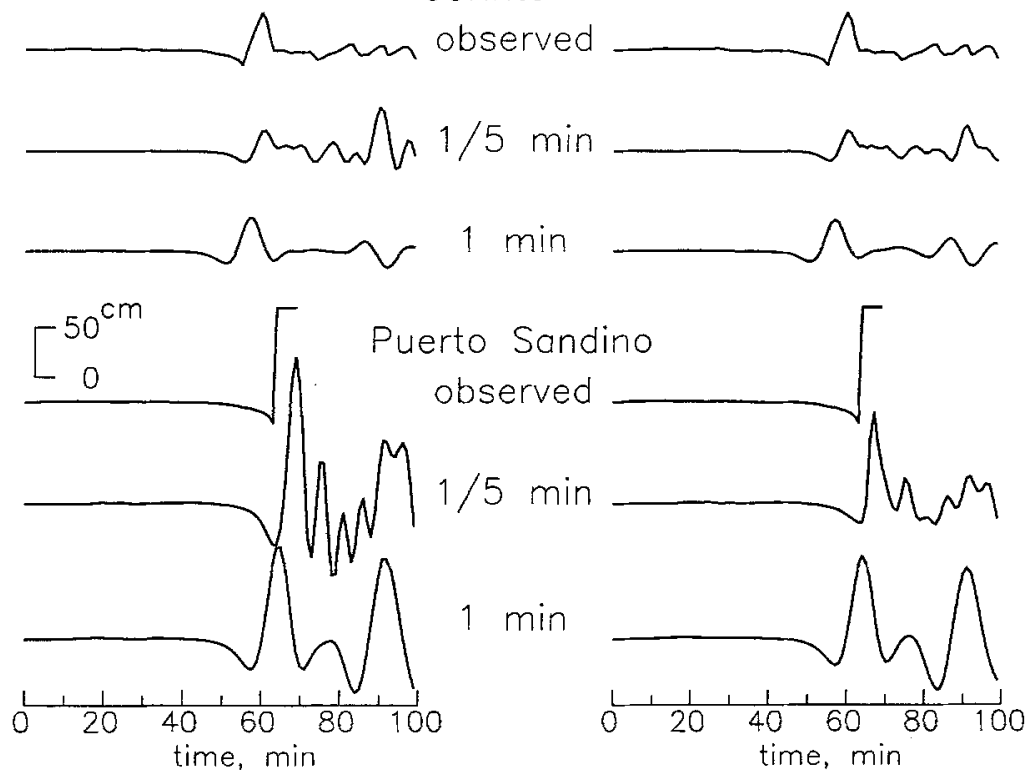

Figure 7

Tsunami waveforms calculated at the tide gauge locations, both 1 minute and $1 / 5$ minute ( 12 seconds) grid systems, are shown for both linear (left) and nonlinear (right) computations. The observed tsunami waveforms, after the tidal components are removed, are also shown.

\subsection{Effect of Bottom Friction}

The effect of the bottom friction is examined next. Figure 8 shows the computed waveforms at the tide gauge stations on the 12 -second grid system for different values of the frictional coefficients: the Manning's coefficients $n=0.03 \mathrm{~m}^{-1 / 3} \mathrm{~s}$, nondimensional frictional coefficients $C_{f}=3 \times 10^{-3}$ and $C_{f}=1 \times 10^{-2}$. The first case assumes the depth-dependent bottom friction while the latter two are depth-independent friction. The waveforms calculated from the linear equation without bottom friction are also shown. The figure shows that the amplitudes become smaller as the friction coefficient becomes larger. This is more evident for later phase, which often registers the largest amplitude. The effect of bottom friction is more evident at Puerto Sandino, where the tsunami amplitude is larger than Corinto.

The above comparison shows that the nonlinear effect, including the bottom friction, plays more important roles for later phases than the first arrival and when tsunami amplitude becomes larger. 


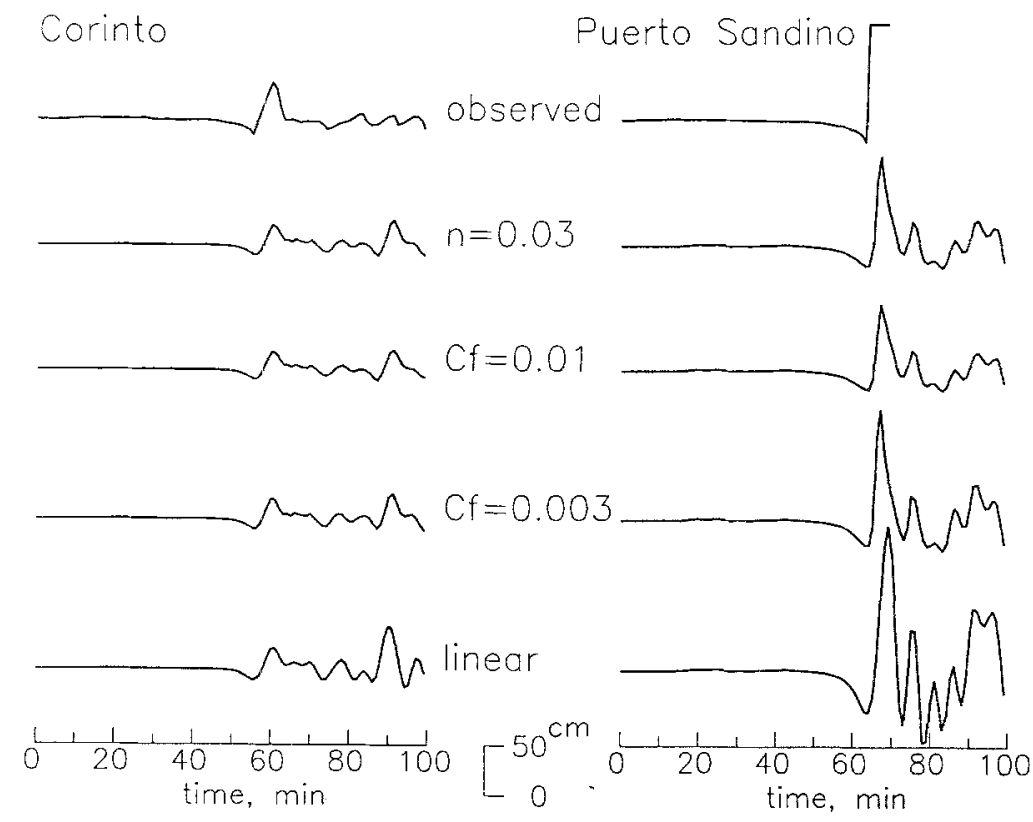

Figure 8

Tsunami waveforms calculated at the tide gauge locations, on $1 / 5$ minute ( 12 seconds) grid system, are shown for different bottom frictional values. The observed tsunami waveforms, after the tidal components are removed, are also shown.

\section{Comparison with Rumup Heights}

The computed tsunami heights are then compared with the maximum runup heights measured along the entire Nicaraguan coast. For the computed heights, the maximum amplitudes within 3 hours of the origin time are used and plotted in Figure 9 for different computations, linear and nonlinear with different bottom friction. The figure shows that the linear computation produces the largest amplitudes, and the case with the largest frictional coefficient $C_{f}=1 \times 10^{-2}$ produces the smallest tsunami heights. The maximum amplitudes for two cases $n=0.03 \mathrm{~m}^{-1 / 3} \mathrm{~s}$ and $C_{f}=3 \times 10^{-3}$ are almost identical. The difference between the two extreme cases, linear and $C_{f}=1 \times 10^{-2}$, is as large as $0.8 \mathrm{~m}$, or $70 \%$ of the amplitude.

The figure also shows the observed runup heights above mean sea level (MSL) compiled by ABE et al. (1993) and BAPTISTA et al. (1993). The tsunami arrived about an hour after the high tide when the sea level was about 50 to $80 \mathrm{~cm}$ above MSL, depending on the location and the actual arrival time of the maximum tsunamis. Even when we consider this correction, the observed runup heights are much larger than the computed heights, by about a factor of 3 . In other words, the average amplification factor is 3 . 


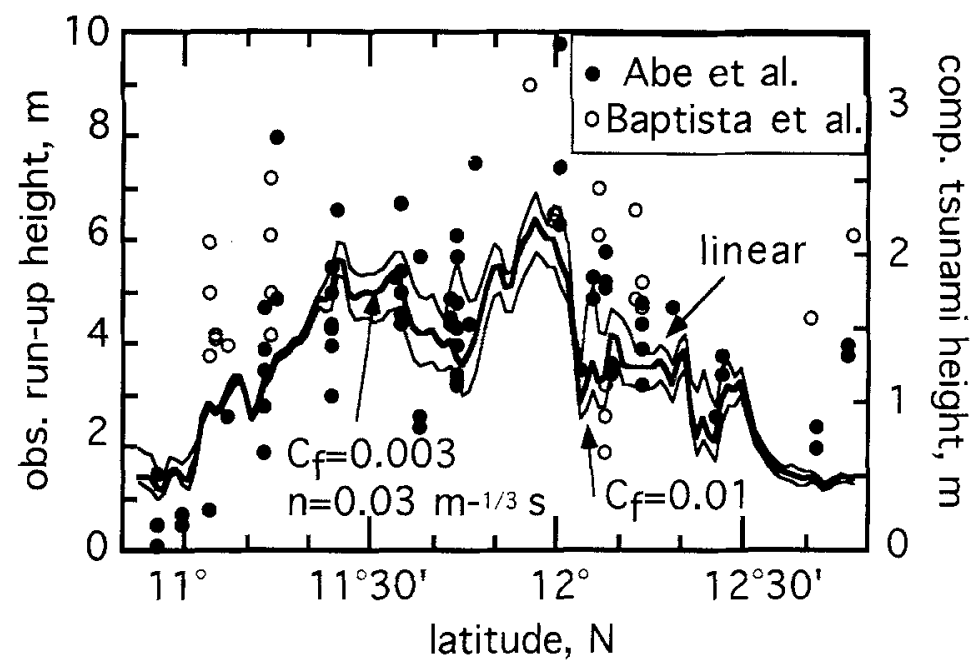

Figure 9

Calculated maximum amplitudes from different bottom frictional values along the Nicaraguan coast. The observed runup heights (ABE et al., 1993 and BAPTISTA et al., 1993) are also shown with a different scale.

The tsunami runup heights were measured in the vicinity of the tide gauge stations at Corinto and Puerto Sandino (ABE et al., 1993). At Corinto, the runup height was $2.7 \mathrm{~m}$ above MSL, or about $2 \mathrm{~m}$ above the sea level at the tsunami arrival. This is about 5 times larger than the amplitude $(40 \mathrm{~cm})$ on the tide gauge record. At Puerto Sandino, the observed runup height was $3.7 \mathrm{~m}$ above MSL or $2.9 \mathrm{~m}$ above the sea level at tsunami arrival. The tide gauge went off-scale, which means that the amplitude was at least $1 \mathrm{~m}$. Hence the amplification factor at this site is less than 3 . The average factor 3 , estimated in our computation, lies between these observed values.

There is no simple theoretical work to compare the predicted tsunami heights and the runup heights. IMAMURA et al. (1993) assumed that the factor is 2, based on experimental data on a beach with slope of $1 / 10$. TITOV and SYNOLAKIS (1993) combined a two-dimensional linear computation with a one-dimensional nonlinear runup computation and successfully reproduced the tsunami runup heights from a source model of IMAMURA et al. (1993), indicating that the amplification factor becomes one if runup calculation is made on a smaller grid size. Hence the amplification factor estimated above is not to be taken as universal, but may be a function of grid size of computation. SATAKE and TANIOKA (1995) indeed show for the 1993 Hokkaido tsunami that the computed maximum tsunami heights are larger when smaller grids are used. 


\section{Conclusions}

Both linear and nonlinear computations of tsunami propagation are made for the Nicaragua earthquake as a test case. The comparisons show that

(1) In order to reproduce tsunami waveforms on tide gauges, the use of detailed bathymetry data with a small grid size is more effective than to include nonlinear terms in the tsunami computation. This is probably because of the small amplitude of tsunamis relative to the water depth at the tide gauges.

(2) For maximum amplitude of tsunamis, the linear computation produces larger amplitudes than the nonlinear computations. In the present case, the depth-independent bottom frictional value of $C_{f}=3 \times 10^{-3}$ and Manning's coefficient $n=0.03 \mathrm{~m}^{-1 / 3} \mathrm{~s}$ gave very similar maximum amplitudes.

(3) The observed tsunami runup heights are still much larger than the computed maximum amplitudes using nonlinear equation. The amplification factor, in the present case with a grid size of 1 minute, is 3 on the average; the factor however may depend on the grid size used for the computation.

In order to make tsunami computation comparable to the observed runup heights, we must use runup calculations. This involves an approximation of water flux on the moving boundary and requires very fine grids of topography as well as bathymetry (e.g., Shuro, 1991; Titov and Synolakis, 1993). While such a computation has become possible, an alternative way is to apply an appropriate amplification factor to the computed tsunami amplitude on a coarse grid system. More comparisons of the observed runup heights with computed tsunami amplitudes on various types of coast are needed to estimate the appropriate amplification factor.

\section{Acknowledgments}

I thank Antonio Baptista, Fumihiko Imamura, Costas Synolakis and Yuichiro Tanioka for helpful discussion and/or comments on the manuscript. This work was supported by National Science Foundation (EAR-9117800 and EAR-9405767).

\section{REFERENCES}

Abe, Ku., Abe, Ka., Tsujl, Y. Imamura, F., Katao, H., Ilo Y., Satake, K., Bourgeois, J. Noguera, E., and Estrada, F. (1993), Field Survey of the Nicaragua Earthquake and Tsunami of 2 September 1992, Bull. Earthq. Res. Inst., Univ. Tokyo 68, 23-70 (in Japanese).

Aida, I., Tsubokawa, H., and Kawaguchi, M. (1988), Numerical Experiments on Behavior of Tsunamis Exceeding the Design Height of a Sea Wall: Case Studies for Matsuzaki, Shizuoka Prefecture and Taro, Iwate Prefecture, Zisin, J. Seismol. Soc. Japan 41, 343-350 (in Japanese).

Baptista, A. M., Priest, G. R., and Murty, T. S. (1993), Field Survey of the 1992 Nicaragua Tsumami, Marine Geodesy 16, 169-203. 
BAptista, A. M., Westerink, J. J., and Turner, P. J. (1989), Tides in the English Channel and Southern North Sea. A Frequency Domain Analysis Using Model TEA-NL, Adv. Water Resources 12, $166-183$.

Dronkers, J. J., Tidal Computations in Rivers and Coastal Waters (North-Holland Publishing Company, 1964).

Ide, S., Imamura, F., Yoshida, Y., and Abe K. (1993), Source Characteristics of the Nicaragua Tsunami Earthquake of September 2, 1992, Geophys. Res. Lett. 20, 863-866.

Imamura, F., Shuto, N., Ide S., Yoshida, Y., and ABE, K. (1993), Estimate of the Tsunami Source of the 1992 Nicaragua Earthquake from Tsunami Data, Geophys. Res. Lett. 20, 1515-1518.

KaJiura, K. (1984), On Runup of Solitary Waves. Tsunami Engin. Tech. Rep., Tohoku Univ. 1, 49-62 (in Japanese).

KANAMORI, H., and KIKUCHI, M. (1993), The 1992 Nicaragua Earthquake: A Slow Tsunami Earthquake Associated with Subducted Sediments, Nature 361, 714-716.

Kikuchi, M., and Kanamori, H. (1995), Source Characteristics of the 1992 Nicaragua Tsunami Earthquake Inferred from Teleseismic Body Waves, Pure and Appl. Geophys, this issue.

Kowalik, Z., and Murty, T. S., Numerical Modeling of Ocean Dynamics (World Scientific, 1993).

Kowalik, Z., and WhitMore, P. M. (1991), An Investigation of Two Tsunamis Recorded at Adak, Alaska, Sci. Tsunami Hazards 9, 67-83.

MADER, C. L., Numerical Modeling of Water Waves (Univ. California Press, 1988).

OKaDA, Y. (1985), Surface Deformation due to Shear and Tensile Faults in a Half-space, Bull Seismol. Soc. Am. 75, 1135-1154.

Press, W. H., Teukolsky, S. A., Vetterling, W. T., and Flannery, B. P., Numerical Recipes in FORTRAN: The Art of Scientific Computing (Cambridge Univ. Press, 1992).

SATAKE, K. (1989), Inversion of Tsunami Waveforms for the Estimation of Heterogeneous Fault Motion of Large Submarine Earthquakes: The 1968 Tokachi-oki and the 1983 Japan Sea Earthquakes, J. Geophys. Res. 94, 5627-5636.

SATAKE, K. (1994), Mechanism of the 1992 Nicaragua Tsunami Earthquake, Geophys. Res. Lett. 21, $2519-2522$.

Satake, K., Bourgeois, J., Abe, Ku., Abe, Ka., Tsuji, Y., Imamura, F., Iio, Y., Katao, H., Noguera, E., and EstradA, F. (1993), Tsunami Field Survey of the 1992 Nicaragua Earthquake, EOS, Trans. Am. Geophys. Union 74, 156-157.

SatAKe, K., and TANIOKA, Y., (1995), Generation and Propagation Characteristics of the 1993 Hokkaido Nansei-oki Earthquake Tsunamis, Pure and Appl. Geophys., this issue.

Shuto, N. (1991), Numerical Simulation of Tsunamis - Its Present and Near Future, Natural Hazards 4, $171-191$.

SYnolakis, C. E., and Skjelbrein, J. E., (1993), Evolution of Maximum Amplitude of Solitary Waves on Plane Beaches, J. Waterway, Port, Coastal and Ocean Engin. 119, 323-342.

Tadepalli, S., and SyNolakis, C. E. (1994), The Runup of $N$ Waves on Sloping Beaches, Proc. R. Soc. Lond. A. 445, 99-112.

Titov, V. V., and SYNolakis, C. E., A numerical study of wave runup of the September 2, 1992 Nicaraguan tsunami, Proc. IUGG/IOC Inter. Tsunami Symposium, (Wakayama, Japan, 1993) pp. $627-635$.

Velasco, A. A., Ammon, C. J., LAY, T., and ZhaNG, J. (1994), Imaging a Slow Bilateral Rupture with Broadband Seismic Waves: The September 2, 1992 Nicaraguan Tsunami Earthquake, Geophys. Res. Lett. 21, 2629-2632.

(Received August 24, 1994, revised February 24, 1995, accepted April 25, 1995) 